\title{
Prevention of osteocyte and osteoblast apoptosis by bisphosphonates and calcitonin
}

\author{
Lilian I. Plotkin, ${ }^{1}$ Robert S. Weinstein, ${ }^{1,2}$ A. Michael Parfitt, ${ }^{1}$ Paula K. Roberson, ${ }^{1}$ \\ Stavros C. Manolagas, ${ }^{1,2}$ and Teresita Bellido ${ }^{1}$
${ }^{1}$ Division of Endocrinology and Metabolism, Center for Osteoporosis and Metabolic Bone Diseases, University of Arkansas for Medical Sciences; and
${ }^{2}$ Central Arkansas Veterans Health Care System; Little Rock, Arkansas 72205, USA \\ Address correspondence to: Teresita Bellido, Division of Endocrinology and Metabolism, University of Arkansas for Medical Sciences, \\ 4301 West Markham, Mail Slot 587, Little Rock, Arkansas 72205, USA. Phone: (501) 686-8971; Fax: (501) 686-8148; \\ E-mail: TMBELLIDO@LIFE.UAMS.EDU.
}

Received for publication March 12, 1999, and accepted in revised form October 7, 1999.

\begin{abstract}
Glucocorticoid-induced osteoporosis may be due, in part, to increased apoptosis of osteocytes and osteoblasts, and bisphosphonates (BPs) are effective in the management of this condition. We have tested the hypothesis that BPs suppress apoptosis in these cell types. Etidronate, alendronate, pamidronate, olpadronate, or amino-olpadronate (IG9402, a bisphosphonate that lacks antiresorptive activity) at $10^{-9}$ to $10^{-6} \mathrm{M}$ prevented apoptosis of murine osteocytic MLO-Y4 cells, whether it was induced by etoposide, TNF- $\alpha$, or the synthetic glucocorticoid dexamethasone. BPs also inhibited apoptosis of primary murine osteoblastic cells isolated from calvaria. Similar antiapoptotic effects on MLO-Y4 and osteoblastic cells were seen with nanomolar concentrations of the peptide hormone calcitonin. The antiapoptotic effect of BPs and calcitonin was associated with a rapid increase in the phosphorylated fraction of extracellular signal regulated kinases (ERKs) and was blocked by specific inhibitors of ERK activation. Consistent with these in vitro results, alendronate abolished the increased prevalence of apoptosis in vertebral cancellous bone osteocytes and osteoblasts that follows prednisolone administration to mice. These results suggest that the therapeutic efficacy of BPs or calcitonin in diseases such as glucocorticoidinduced osteoporosis may be due, in part, to their ability to prevent osteocyte and osteoblast apoptosis.
\end{abstract}

J. Clin. Invest. 104:1363-1374 (1999).

\section{Introduction}

Over the past 3 decades, bisphosphonates (BPs) - stable analogs of pyrophosphate - and calcitonin have been developed as potent inhibitors of bone resorption and effective agents for the management of osteoporosis and other bone diseases (1-4). Decreased osteoclast progenitor development, decreased osteoclast recruitment, and promotion of apoptosis of mature osteoclasts leading to decreased bone remodeling are thought to be the main mechanisms of the antiresorptive actions of BPs (5-8). Likewise, disruption of osteoclast function is thought to be the main mechanism for the antiresorptive actions of calcitonin (4). At least some of the effects of BPs on osteoclast development and function might be mediated indirectly through actions on cells of the osteoblastic lineage. Thus, pretreatment of osteoblastic cells with BPs inhibits the formation of osteoclast-like cells from their marrow or spleen precursors (9), as well as osteoclastresorbing activity in cocultures with mature osteoclasts $(10,11)$. These inhibitory effects can be reproduced by addition of conditioned media from BP-treated osteoblastic cells to the cultures, suggesting that BPs promote the release of factors that inhibit osteoclast formation and activity (9-11).

Long-term treatment of human and nonhuman primates with BPs increases wall thickness, an index of focally increased osteoblast numbers or activity, resulting in more complete refilling of resorption cavities (12-14). This evidence has raised the possibility that BPs do more than simply reduce remodeling space and that they may possess anabolic activity (15).

Antiresorptive agents such as BPs and calcitonin, as well as estrogen, decrease fracture incidence disproportionally to their effect on bone mass (16). This suggests an additional effect on bone strength unrelated to effects on bone mineral density (BMD). However, an explanation for this phenomenon remains elusive. Osteocytes, differentiated osteoblasts regularly spaced throughout the mineralized matrix, are believed to detect bone microdamage and to transmit signals leading to its repair $(17,18)$. Disruption of the osteocyte network could compromise this mechanism, leading to microdamage accumulation and increased bone fragility. Such a defect in bone quality could account for the higher incidence of fractures in glucocorticoid-treated patients compared with postmenopausal women, even though BMD in the former is relatively higher $(19,20)$. Based on the observations that glucocorticoid excess increases the prevalence of osteocyte and osteoblast apoptosis $(21,22)$ and that BPs are effective in the management of this condition (23-25), we have hypothesized that BPs and perhaps other antiresorptive agents such as calcitonin prevent osteocyte and osteoblast apoptosis. We present evidence that BPs and calcitonin exert antiapoptotic 
effects on osteocytic cells and mature osteoblasts in vitro and that BPs also prevent osteocyte and osteoblast apoptosis induced by glucocorticoid excess in vivo.

\section{Methods}

Materials. The bisphosphonates used in this study were provided by Gador S.A. (Buenos Aires, Argentina). Bovine calf serum was purchased from Hyclone Laboratories (Logan, Utah, USA). FBS was purchased from Summit (Collins, Colorado, USA). Recombinant murine TNF- $\alpha$ was obtained from Genzyme Pharmaceuticals (Cambridge, Massachusetts, USA). Phenol red-free $\alpha$ MEM and trypsin-EDTA were purchased from GIBCO BRL (Gaithersburg, Maryland, USA). Etoposide, geneticin

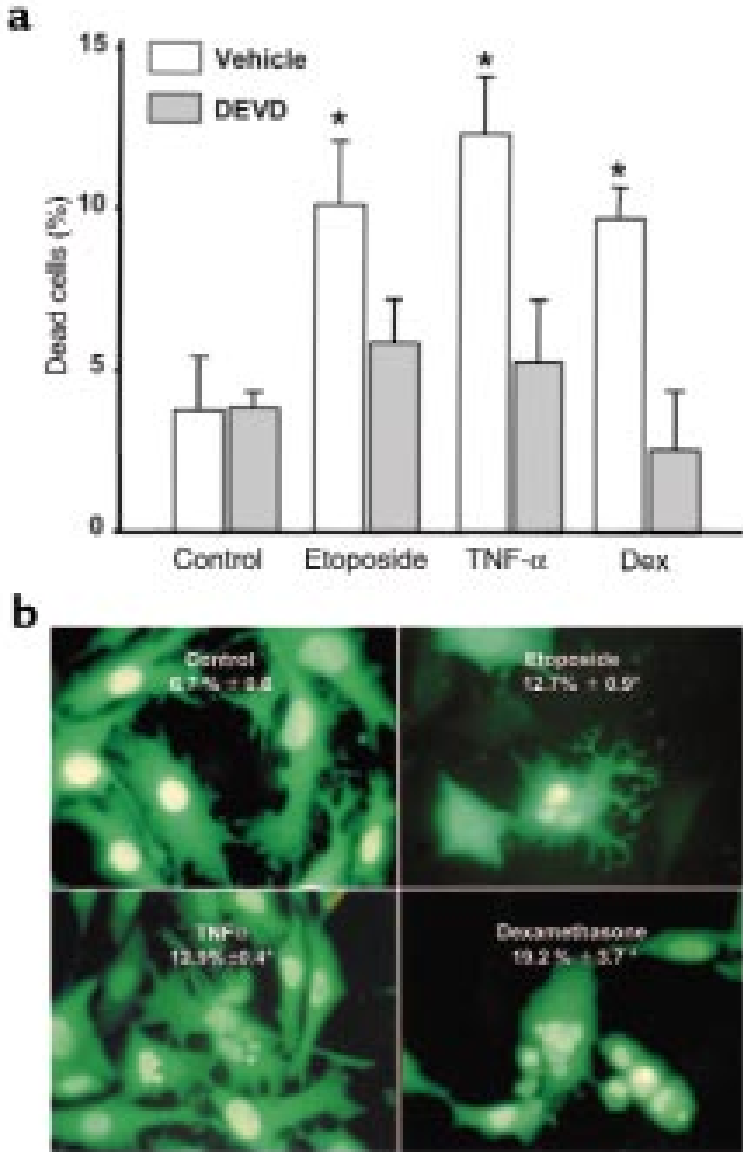

\section{Figure 1}

Demonstration of MLO-Y4 cell apoptosis. (a) MLO-Y4 cells were incubated for 1 hour in vehicle or 50 nM DEVD-CHO. Subsequently, etoposide, TNF- $\alpha$, or dexamethasone (Dex) were added at final concentrations of $50 \mu \mathrm{M}, 1 \mathrm{nM}$, or $10^{-6} \mathrm{M}$, respectively, and cells were incubated for an additional 6 hours. Dead cells were enumerated by trypan blue uptake, as described in Methods. Bars represent the mean \pm SD of 3 independent measurements. Data were analyzed by 1 -way ANOVA. ${ }^{*} P<0.05$ versus control (Student Newman-Keuls method). (b) MLO-Y4 cells stably transduced with GFP were maintained for 6 hours in the presence of vehicle, 50 $\mu \mathrm{M}$ etoposide, $1 \mathrm{nM}$ TNF- $\alpha$, or $10^{-6} \mathrm{M}$ dexamethasone. Numbers indicate the percentage of cells undergoing apoptosis, as determined by evaluating the nuclear morphology of more than 500 cells in fields selected by systematic random sampling. Results are means \pm SD of 3 independent experiments. Original magnification: $\times 400$. Data were analyzed by 1 -way ANOVA. ${ }^{*} P<0.05$ versus control (Student Newman-Keuls method).
(G418), and calf skin collagen type I were obtained from Sigma Chemical Co. (St. Louis, Missouri, USA). Collagenase type 2 was purchased from Worthington Biochemical Corp. (Freehold, New Jersey, USA). PD98059 was purchased from New England Biolabs Inc. (Beverly, Massachusetts, USA). U0126 was kindly provided by J.M. Trzaskos (DuPont Merck Research Laboratories, Wilmington, Delaware, USA). The caspase-3 inhibitor Asp-GluVal-Asp-aldehyde (DEVD-CHO) was purchased from Biomol Research Laboratories, Inc. (Plymouth Meeting, Pennsylvania, USA). DEVD conjugated with 7-amino-4trifluoromethyl coumarin (DEVD-AFC) was from BioRad Laboratories, Inc. (Hercules, California, USA). The mouse $\mathrm{mAb}$ anti-phospho-extracellular signal regulated kinases (ERKs) 1 and 2 (ERK1/2), the rabbit polyclonal antibody antiphosphorylated and unphosphorylated ERK1/2, and secondary anti-mouse or anti-rabbit antibodies conjugated with horseradish peroxidase were purchased from Santa Cruz Biotechnology (Santa Cruz, California, USA). Salmon calcitonin (sCT) was purchased from Bachem California (Torrance, California, USA). ${ }^{125}$ I was obtained from Amersham Life Sciences Inc. (Arlington Heights, Illinois, USA).

Cell culture. The murine long bone-derived osteocytic cell line MLO-Y4 was provided by L. Bonewald (University of Texas Health Center at San Antonio, San Antonio, Texas, USA). Cells were cultured in phenol red-free aMEM supplemented with 5\% FBS, 5\% bovine calf serum, $100 \mathrm{U} / \mathrm{mL}$ penicillin, and $100 \mu \mathrm{g} / \mathrm{mL}$ streptomycin. Cells were plated at $1 \times 10^{4}$ to $2 \times 10^{4}$ cells $/ \mathrm{cm}^{2}$ on collagen type I-coated plates, as described previously (26). Murine calvaria cells were obtained from neonatal (3- to 6-day-old) C57BL/6J mice by controlled digestion with collagenase, as described previously (27). After isolation, cells were cultured in $10 \%$ FBS at $1 \times 10^{4}$ to $2 \times 10^{4}$ cells $/ \mathrm{cm}^{2}$ until $90-95 \%$ confluence. Subsequently, cells were harvested and frozen for later use. UMR-106-06 cells were cultured in phenol red-free MEM supplemented with $10 \%$ FBS, $1 \%$ nonessential amino acids, 100 $\mathrm{U} / \mathrm{mL}$ penicillin, and $100 \mu \mathrm{g} / \mathrm{mL}$ streptomycin (28).

Establishment of MLO-Y4 cells stably transduced with green fluorescent protein. The retroviral vector containing the nuclear green fluorescent protein (GFP) was provided by C. O'Brien (University of Arkansas for Medical Sciences, Little Rock, Arkansas, USA). The SV40 large T antigen nuclear localization sequence (29) was attached to the $\mathrm{COOH}$-terminus of the cDNA construct encoding GFP and subcloned into the pLXSN retroviral vector (CLONTECH Laboratories Inc., Palo Alto, California, USA). The plasmid harboring the retroviral construct was transiently transfected into the packaging cell line Phoenix Eco (30) using SuperFect (QIAGEN Inc., Valencia, California, USA). Supernatants containing retroviral particles were collected 24-48 hours after transfection and were used immediately to infect cell cultures. Subconfluent MLO-Y4 osteocytic cells were exposed to viral supernatants in the presence of $8 \mu \mathrm{g} / \mathrm{mL}$ polybrene for 8 hours and then incubated in fresh culture medium for 16 hours. Subsequently, cells were exposed to the supernatants containing the viral particles once more before being trypsinized and plated at low density. Transduced cells were selected by culturing them in the presence of 400 $\mu \mathrm{g} / \mathrm{mL}$ of $\mathrm{G} 418$ for 3 weeks. 

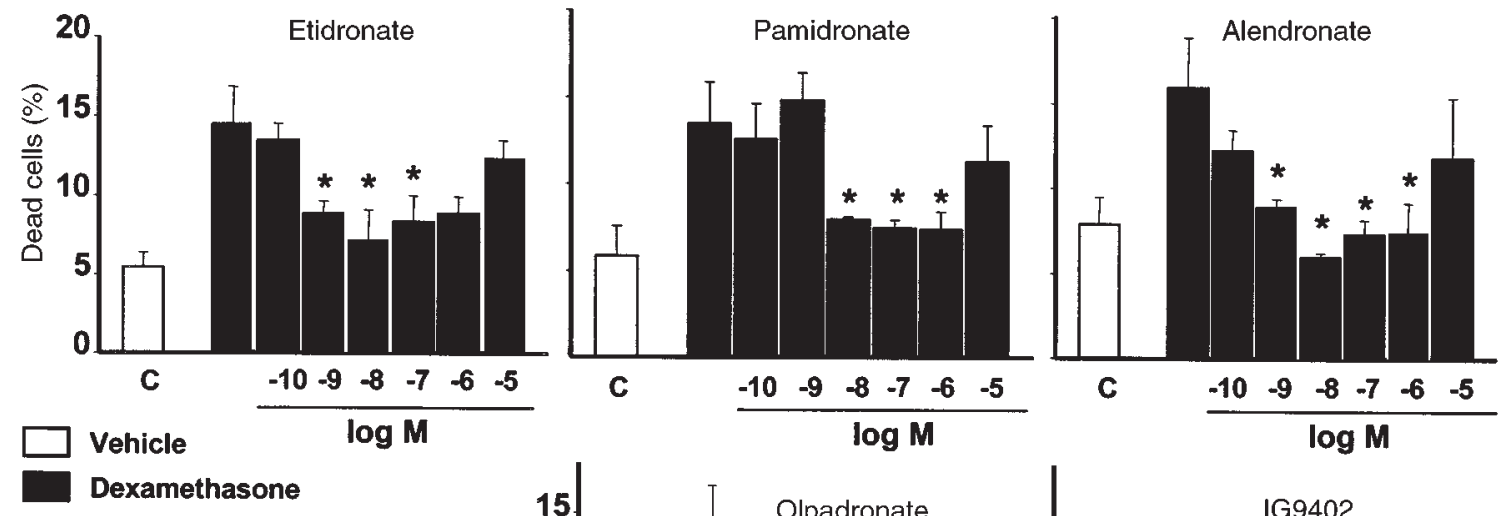

Figure 2

Bisphosphonates inhibit glucocorticoid-induced apoptosis of MLO-Y4 osteocytic cells. MLO-Y4 cells were pretreated with the indicated concentrations of BPs for 1 hour, and subsequently dexamethasone $\left(10^{-6} \mathrm{M}\right.$ final concentration) was added for 6 hours. The percentage of dead cells was determined by trypan blue uptake, as in Figure 1a. Bars represent the mean \pm SD of 3 independent measurements. Data were analyzed by 1 -way ANOVA. ${ }^{*} P<0.05$ versus dexamethasone alone (Student Newman-Keuls method).
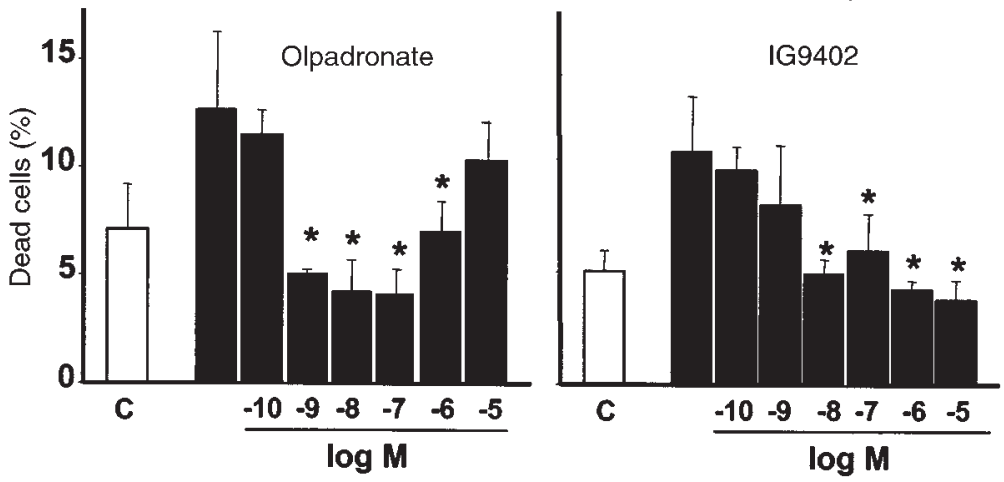

Quantification of apoptotic cells. MLO-Y4 osteocytic cells and calvaria osteoblastic cells were treated for 1 hour in the absence or presence of different BPs or sCT. Subsequently, dexamethasone, etoposide, or TNF- $\alpha$ was added to obtain final concentrations of $10^{-6} \mathrm{M}, 50 \mu \mathrm{M}$, or $1 \mathrm{nM}$, respectively, and cells were incubated for additional 6 hours. The effect of PD98059 $(50 \mu \mathrm{M})$ or UO126 $(1 \mu \mathrm{M})$ was evaluated by pretreating the cells with the inhibitors for 30 minutes before adding the BPs or sCT. In the experiment using the membrane permeable caspase inhibitor DEVD, cells were cultured for 1 hour with 50 nM DEVD-CHO, and subsequently the proapoptotic agents were added to reach the final concentrations already indicated here. MLO-Y4 cells stably transduced with nuclear GFP were fixed in neutral buffer formalin for 8 minutes, and apoptosis was assessed by enumerating cells exhibiting chromatin condensation and nuclear fragmentation under a fluorescent microscope. At least 500 cells from fields selected by systematic random sampling were examined for each experimental condition. For the detection of apoptotic cells using the transferasemediated biotin-dUTP nick end-labeling (TUNEL) reaction with Klenow terminal deoxynucleotidyl transferase (Oncogene Research Products, Cambridge, Massachusetts, USA), MLO-Y4 cells were cultured with either vehicle or $10^{-7} \mathrm{M}$ alendronate for 1 hour, and subsequently dexamethasone was added to reach $10^{-6} \mathrm{M}$. After 6 hours, cells were fixed in neutral buffer formalin for 10 minutes followed by $80 \%$ ethanol for 1 hour. The TUNEL reaction was performed according to the manufacturer's instructions, using $0.15 \% \mathrm{CuSO}_{4}$ for color enhancement. Negative controls were made by omitting the transferase from the reaction. Cells presenting brown nuclear staining were considered positive. More than 500 cells per condition were analyzed. Apoptosis of parental MLO-Y4 or calvaria cells was quantified by trypan blue staining (31).
Nonadherent cells were combined with adherent cells released from the culture dish using trypsin-EDTA, resuspended in medium containing serum, and collected by centrifugation. Subsequently, 0.04\% trypan blue was added and the percentage of cells exhibiting both nuclear and cytoplasmic staining was determined using a hemocytometer. At least 100 cells per condition were counted.

Caspase-3 activity. Caspase- 3 activity was measured by determining the degradation of the fluorometric substrate DEVD, which contains the amino acid sequence of the caspase-3 cleavage site in poly(ADP-ribose)polymerase (32), conjugated with DEVD-AFC. Cells were lysed in $20 \mathrm{mM}$ Tris- $\mathrm{HCl}$ ( $\mathrm{pH} 7.5$ ), $150 \mathrm{mM} \mathrm{NaCl}, 1 \mathrm{mM}$ EDTA, $10 \mathrm{mM} \mathrm{NaF}, 1 \mathrm{mM}$ sodium orthovanadate, 5 $\mu \mathrm{g} / \mathrm{mL}$ leupeptin, $0.14 \mathrm{U} / \mathrm{mL}$ aprotinin, $1 \mathrm{mM}$ phenylmethylsulfonylfluoride, and 1\% Triton X-100. Protein concentration was measured using a Bio-Rad detergent-compatible kit (Bio-Rad). Lysates (100 $\mu$ g protein) were incubated with $50 \mu \mathrm{M}$ DEVD-AFC in $50 \mathrm{mM}$ HEPES (pH 7.4), $100 \mathrm{mM} \mathrm{NaCl}, 0.1 \%$ CHAPS, $10 \mathrm{mM}$ DTT, 1 mM EDTA, and 10\% glycerol, in the absence or presence of the irreversible inhibitor DEVD-CHO for 60 minutes. The released fluorescent AFC was measured in a microplate fluorescence reader FL500 (Bio Tek Instruments, Winooski, Vermont, USA) with excitation/emission wavelengths of $340 / 542 \mathrm{~nm}$.

Western blot analysis. Semiconfluent (75-80\%) MLO-Y4 cells were incubated in medium without serum (in the absence or presence of $50 \mu \mathrm{M}$ PD98059 or $1 \mu \mathrm{M}$ UO126) for 25 minutes and treated with $10^{-7} \mathrm{M}$ alendronate, IG9402, or etidronate for the last $0.5,1,2,5,10$, or 15 minutes, or with $5 \mathrm{ng} / \mathrm{mL} \mathrm{sCT}$ for the last $2,5,10$, or $15 \mathrm{~min}$ utes. Monolayers were washed with cold $20 \mathrm{mM}$ Tris- $\mathrm{HCl}$ ( $\mathrm{pH} 7.5$ ), $150 \mathrm{mM} \mathrm{NaCl}$, and $1 \mathrm{mM}$ sodium orthovanadate and lysed in the lysis buffer already described here. Insoluble material was pelleted in a microcentrifuge at $16,000 \mathrm{~g}$ 
for 10 minutes. The phosphorylation status of ERK1/2 was analyzed by immunoblotting, as described previously (27). Proteins $(10 \mu \mathrm{g})$ were separated on $7.5 \%$ SDS-poly-
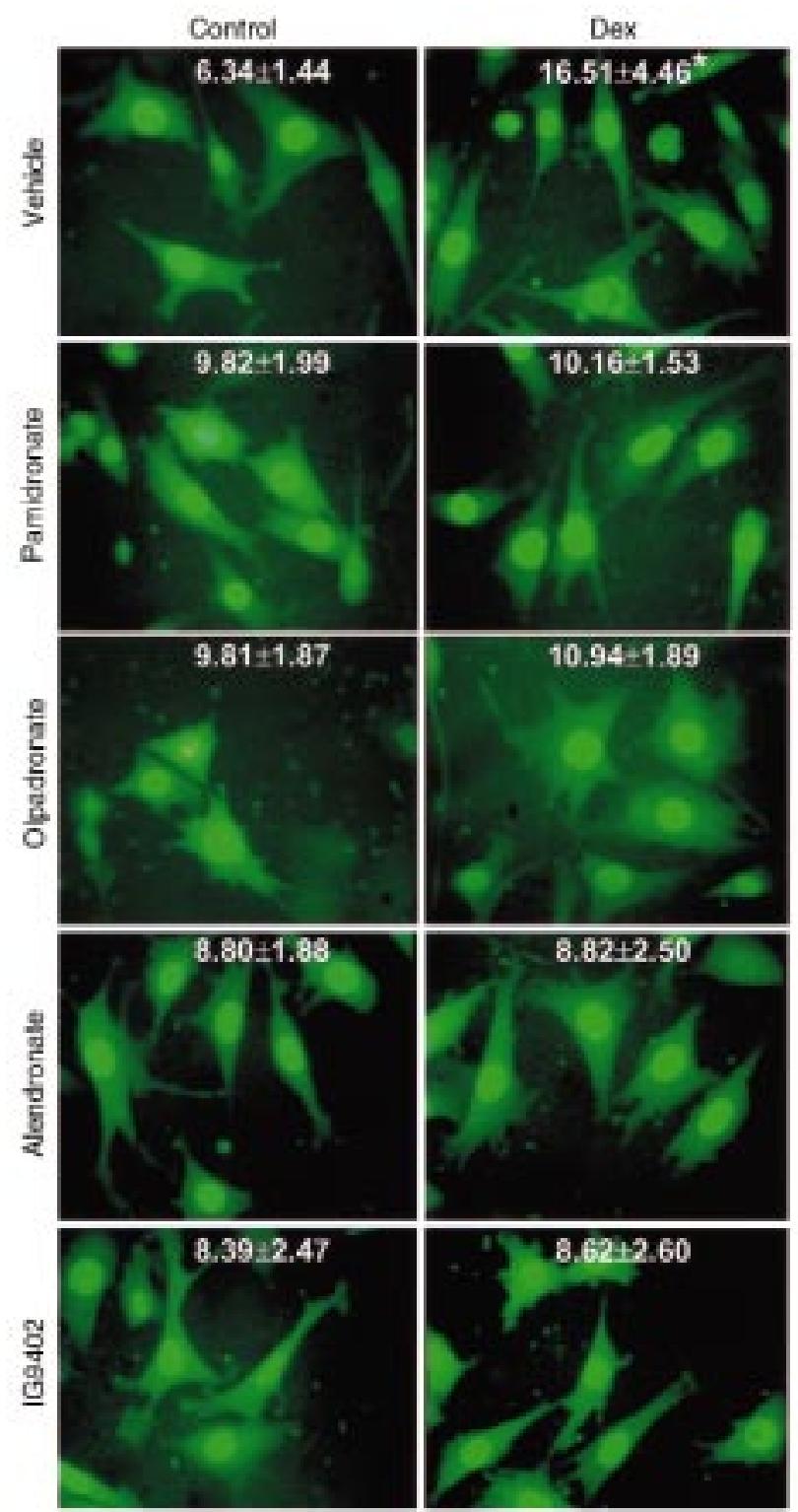

Figure 3

Bisphosphonates inhibit glucocorticoid-induced apoptosis of MLO-Y4 osteocytic cells. MLO-Y4 cells stably transduced with GFP were treated for 1 hour with $10^{-7} \mathrm{M}$ concentration of the indicated bisphosphonates, followed by addition of $10^{-6} \mathrm{M}$ dexamethasone. After 6 hours, cells were fixed. Numbers indicate the percentage of cells undergoing apoptosis as determined by evaluating the nuclear morphology of more than 500 cells in fields selected by systematic random in at least 3 different experiments (mean $\pm S D$ ). Original magnification: $\times 400$. Data were analyzed by 1 -way ANOVA. ${ }^{*} P<0.05$ versus control (Student Newman-Keuls method). The effect of bisphosphonates on the proportion of MLO-Y4 cells exhibiting chromatin condensation and/or nuclear fragmentation in the absence of dexamethasone was also analyzed using exact $\chi^{2}$ tests in 3 experiments with pamidronate, olpadronate, or IG9402, and in 6 experiments with alendronate. Bonferroni adjusted pairwise comparisons between untreated groups and groups treated with bisphosphonates yielded no significant differences when the experiments were analyzed individually; however, differences were significant when all experiments for given treatment condition were combined in a stratified $\chi^{2}$ analysis (see the text). acrylamide gels and electrotransferred to a polyvinylidene difluoride membrane. Immunoblotting was performed using a mouse $\mathrm{mAb}$ recognizing tyrosine phosphorylated ERK1/2, or a rabbit polyclonal antibody recognizing total ERK1/2, followed by incubation with either an anti-mouse or an anti-rabbit antibody conjugated with horseradish peroxidase. Blots were developed using chemiluminescence according to the manufacturer's recommendations. Quantitation of the intensity of the bands in the autoradiograms was performed using a scanner (Microtek Laboratory, Redondo Beach, California, USA).

Calcitonin binding assay. SCT was labeled with ${ }^{125} \mathrm{I}$ in the presence of chloramine T using a standard protocol. Binding of [ $\left.{ }^{125} \mathrm{I}\right] \mathrm{sCT}$ to MLO-Y4 or UMR-106-06 cells was performed using a whole-cell assay. Cells were harvested by trypsinization, washed twice with PBS, resuspended in culture medium without serum, and incubated in triplicates $\left(1.25 \times 10^{5} /\right.$ tube $)$ with $10^{-8} \mathrm{M}\left[{ }^{125} \mathrm{I}\right] \mathrm{sCT}$ in the absence or presence of 100-fold molar excess of unlabeled $\mathrm{sCT}$, for 1 hour at room temperature. Subsequently, cells were washed 3 times with iced PBS containing $0.2 \%$ BSA, and pellets were obtained by centrifugation at $500 \mathrm{~g}$ for 10 minutes were counted using a $\gamma$-counter.

Cyclic AMP production. The concentration of cAMP in lysates of MLO-Y4 cells upon treatment with sCT was determined using a kit based on the competition for a fixed amount of anti-cAMP antibody between unlabeled cAMP present in the sample and peroxidase-labeled cAMP (Amersham Life Sciences Inc., Arlington Heights, Illinois, USA).

Glucocorticoid administration to mice. Male Swiss Webster mice (Charles River Laboratories, Stone Ridge, New York, USA) were given daily subcutaneous injections of $0.75 \mathrm{mg} / \mathrm{kg}$ per day of alendronate dissolved in saline (4amino-1-hydroxybutylidene-1,1-bisphosphonate; obtained from C.W.G.M. Löwik, University Hospital, Leiden, the Netherlands) beginning 3 days before subcutaneous implantation of $2.1 \mathrm{mg} / \mathrm{kg}$ per day pellets of slowrelease prednisolone (Innovative Research of America, Sarasota, Florida, USA). To adjust for the difference in the metabolic rate in mice compared with that in humans, the daily glucocorticoid dose was divided by the metabolic weight, i.e., the weight in $\mathrm{kg}$ to the $3 / 4$ power $(33,34)$. Expressed in this manner, $2.1 \mathrm{mg} / \mathrm{kg}$ per day of prednisolone is $0.0735 \mathrm{mg} / \mathrm{d}$ given to a $0.035 \mathrm{~kg}$ mouse or $0.909 \mathrm{mg} / \mathrm{kg}^{3 / 4}$, a value quite similar to 0.926 $\mathrm{mg} / \mathrm{kg}^{3 / 4}$, which results when a dose of $20 \mathrm{mg} / \mathrm{d}$ of prednisolone is given to a $60-\mathrm{kg}$ human. One control group received saline injections with placebo pellet implantation, whereas another group received saline injections plus prednisolone pellets. Dual-energy x-ray absorptiometry was used to determine spinal bone mineral density (spinal BMD) at the end of the 56-day experiment, as described previously (21).

Measurement of apoptosis in undecalcified bone sections. Sections of vertebral bone (L1-L5) were mounted on silanecoated glass slides (Scientific Device Laboratory, Inc., Des Plains, Illinois, USA), deplasticized, and incubated in 10 $\mathrm{mM}$ citrate buffer ( $\mathrm{pH} 7.6$ ) in a microwave oven at $98^{\circ} \mathrm{C}$ for 5 minutes (31). Slides were then incubated with $0.5 \%$ pepsin for 30 minutes at $37^{\circ} \mathrm{C}$. Apoptotic cells were detected by the TUNEL reaction in sections counterstained with $1 \%$ methyl green. Cells whose nuclei were clearly brown 
from the streptavidin-horse radish peroxidase conjugate instead of blue-green from the methyl green were interpreted as positive. Plastic-embedded sections of weaned rat mammary tissue were used as a positive control. Negative controls were made by omitting the transferase from the TUNEL reaction. Morphological changes characteristic of apoptosis were carefully examined to minimize ambiguity regarding the interpretation of results. With these precautions, TUNEL has been unequivocally associated with apoptosis and used with DNA fragmentation and immunohistochemical studies to demonstrate apoptosis of osteoblastic cells and osteoblasts both in vitro and in vivo $(21,31)$. Osteocytes were identified inside lacunae in mineralized bone. Osteoblasts were identified as cuboidal cells lining the osteoid-covered trabecular perimeter.

Statistical analysis. Data were analyzed by 1-way ANOVA, and the Student Newman-Keuls method was used to estimate the level of significance of differences between means. The effect of bisphosphonates on the proportion of MLO-Y4 cells exhibiting chromatin condensation and/or nuclear fragmentation in the absence of dexamethasone was also analyzed using exact $\chi^{2}$ tests, adjusting the $P$ values within each experiment using a Bonferroni correction, and stratifying by experiment when combining information across experiments. All $P$ values were compared to an $\alpha$ value of 0.05 to determine significance. To establish whether the effect of BPs was dependent on the proapoptotic agent used, data were analyzed by 2 -way ANOVA in which the 2 variables were the proapoptotic agents (dexamethasone, etoposide, and TNF- $\alpha$ ) and the pretreatments (vehicle, alendronate, and IG9402). The Student Newman-Keuls method was used to estimate the significance of the differences among pretreatments.

\section{Results}

Bisphosphonates inhibit apoptosis of osteocytic cells and osteoblasts. Exposure of MLO-Y4 osteocytic cells to the glucocorticoid dexamethasone $\left(10^{-6} \mathrm{M}\right)$ increased the percentage of cells stained with trypan blue (Figure 1a). As in other in vitro systems (35-37), proapoptotic effects of dexamethasone were also obtained with concentrations between $10^{-7}$ and $10^{-5} \mathrm{M}$. Similar effect was obtained with the inhibitor of DNA repair etoposide, which blocks topoisomerase II activity (38), and with TNF- $\alpha$, an activator of death receptors (39). The increase in cell membrane permeability detected by trypan blue was prevented by DEVD-CHO, a specific inhibitor of caspases that trigger death by apoptosis (40). Consistent with this finding, all the proapoptotic agents used here induced an increase in the percentage of cells exhibiting the characteristic features of apoptosis, i.e., chromatin condensation and nuclear fragmentation, as shown by microscopic examination of MLO-Y4 cells stably transduced with nuclear green fluorescent protein (Figure $1 \mathrm{~b}$ ).

Pretreatment with BPs for 1 hour before addition of dexamethasone inhibited apoptosis, with minimal effective concentrations between $10^{-9}$ and $10^{-8} \mathrm{M}$ (Figure 2). At concentrations higher than $10^{-6} \mathrm{M}$, this inhibitory effect was decreased or lost. Comparable responses were obtained with etidronate and with the aminobisphosphonates alendronate, pamidronate, or olpadronate. Similar biphasic effects of bisphosphonates on osteoblastic
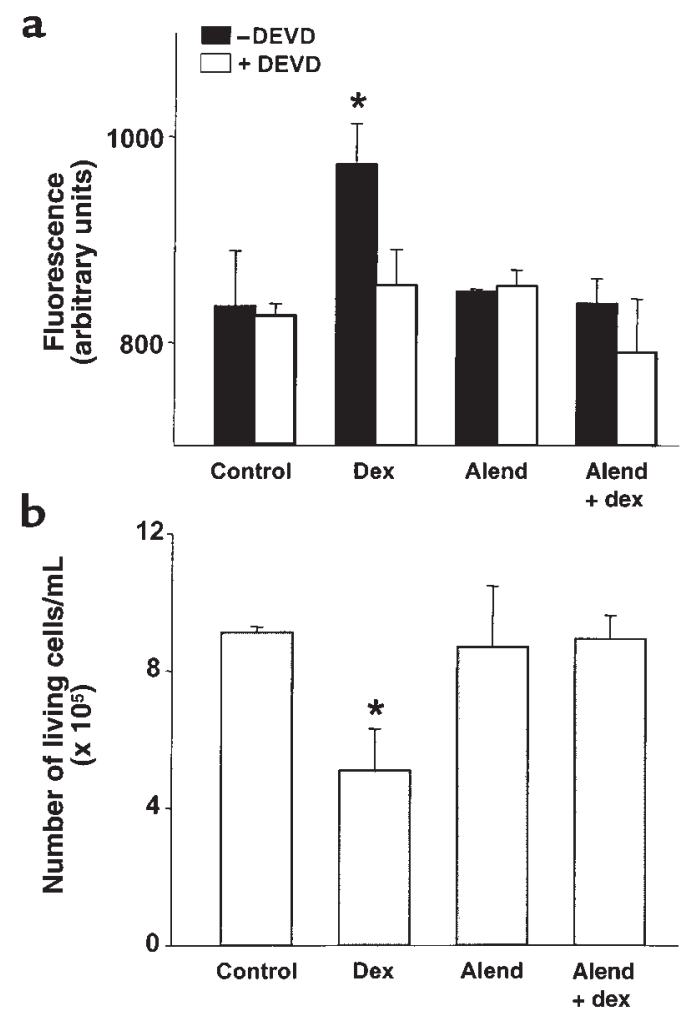

Figure 4

Bisphosphonates inhibit the increase in caspase-3 activity and the decrease in the number of living cells induced by dexamethasone. MLO-Y4 cells were incubated with vehicle or $10^{-7} \mathrm{M}$ alendronate for 1 hour. Subsequently, dexamethasone was added to reach a final concentration of $10^{-6} \mathrm{M}$, and cells were cultured for 16 hours (a) or 24 hours (b). Caspase- 3 activity was determined by measuring the degradation of the fluorometric substrate DEVDAFC in the absence or presence of the irreversible inhibitor DEVD-CHO, as detailed in Methods (a). Cells were harvested by trypsinization, and the number of living cells was scored using an hemocytometer as described in Methods (b). Bars represent the mean $\pm \mathrm{SD}$ of 3 independent measurements. ${ }^{*} P$ $<0.05$ versus control, by ANOVA (Student Newman-Keuls method).

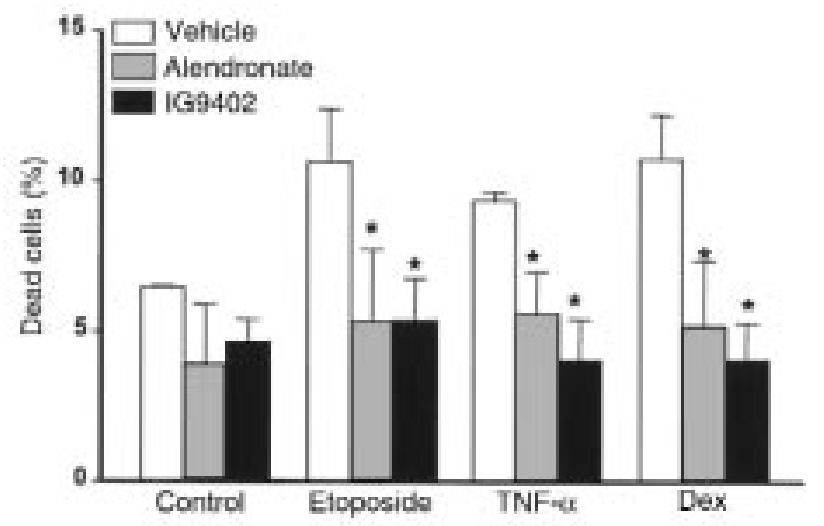

Figure 5

The protective effect of bisphosphonates on osteocytic cells is independent of the proapoptotic stimulus. MLO-Y4 cells were incubated with vehicle, $10^{-7}$ $\mathrm{M}$ alendronate, or IG9402 for 1 hour. Subsequently, etoposide, TNF- $\alpha$, or dexamethasone were added to reach final concentrations of $50 \mu \mathrm{M}, 1 \mathrm{nM}$, or $10^{-6} \mathrm{M}$, respectively, and cells were cultured for 6 hours, as in Figure 1. The percentage of dead cells was determined by trypan blue uptake. Bars represent the mean \pm SD of 3 independent measurements. Data were analyzed by 2 -way ANOVA. No interaction between the proapoptotic agents and the pretreatments was found (at an $\alpha$ level of 0.05 ). ${ }^{*} P<0.05$ versus etoposide, TNF- $\alpha$, or dexamethasone alone (Student Newman-Keuls method). 


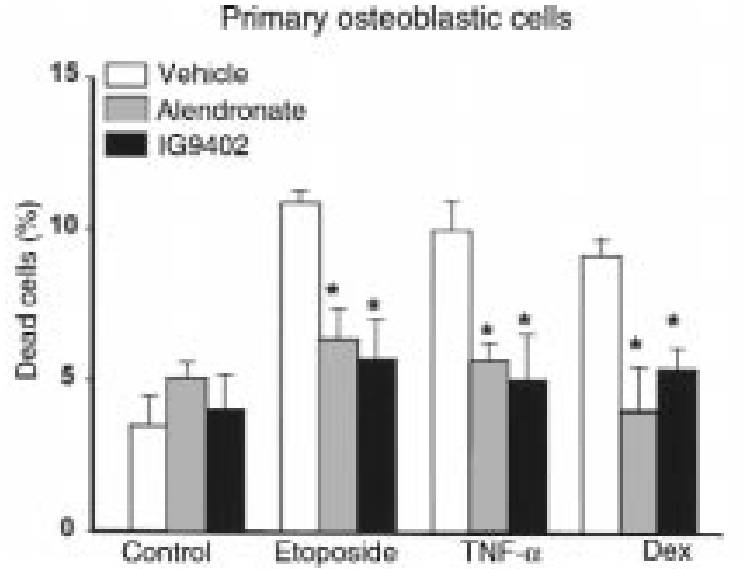

Figure 6

The protective effect of bisphosphonates on osteoblastic cells is independent of the proapoptotic stimulus. This experiment was performed as in Figure 5, but using osteoblastic cells derived from murine calvaria. Bars represent the mean \pm SD of 3 independent measurements. Data were analyzed by 2-way ANOVA. No interaction between the proapoptotic agents and the pretreatments was found (at an $\alpha$ level of 0.05 ). ${ }^{*} P<0.05$ versus etoposide, TNF- $\alpha$, or dexamethasone alone (Student Newman-Keuls method).

cell preparations have been described previously (41-43). Interestingly, amino-olpadronate (IG9402), a compound that lacks antiresorptive activity (44), was also effective. However, unlike the other BPs, the inhibitory effect of IG9402 persisted at high concentrations. Removal of BPs before inducing apoptosis or addition of BPs simultaneously with dexamethasone also prevented the effect of the proapoptotic agent (data not shown). Exposure of MLOY4 cells to $10^{-10}$ to $10^{-3} \mathrm{M}$ alendronate or IG9402 in the absence of proapoptotic stimuli did not affect cell viability (data not shown). The prevention of glucocorticoidinduced apoptosis by BPs was confirmed by examining the nuclear morphology of MLO-Y4 cells stably transduced with nuclear GFP (Figure 3).
Consistent with an antiapoptotic action, alendronate inhibited the dexamethasone-induced increase in caspase-3 activity (Figure 4a) and in the number of TUNELpositive cells (Table 1). Likewise, alendronate prevented the dexamethasone-induced decrease in the number of viable MLO-Y4 cells (as determined by trypan blue uptake) (Figure 4b). Alendronate alone, i.e., in the absence of the proapoptotic stimulus of dexamethasone, did not affect any of these parameters. The small (2-3\%) increase in cells exhibiting chromatin condensation and/or nuclear fragmentation observed in BP-treated cultures compared with untreated cultures was not reproduced by trypan blue uptake (Figure 5) and was not inhibited by DEVD (data not shown), indicating that it was not due to apoptosis. Treatment with bisphosphonates for 6 or 24 hours did not increase the total number of MLO-Y4 cells. However, we cannot exclude the possibility that these agents stimulate osteocytic cell division, as it has been demonstrated for other osteoblastic cell preparations in vitro (42). This could cause an increase in the number of cells with 2 nuclei that could have been scored as exhibiting nuclear fragmentation.

Alendronate or IG9402 also prevented apoptosis of MLO-Y4 cells induced by either etoposide or TNF- $\alpha$ (Figure 5). In full agreement with our earlier observations $(31,45)$, dexamethasone, TNF- $\alpha$, and etoposide induced apoptosis of osteoblastic cells derived from murine calvaria (Figure 6). Similar to their effect on osteocytic cells, alendronate and IG9402 inhibited apoptosis of osteoblastic cells induced by all these agents. No statistical interaction was found between the proapoptotic agents and the different pretreatments (vehicle, alendronate, and IG9402), indicating that the inhibitory effect of BPs on osteocytes and osteoblasts was independent of the proapoptotic agent.

The mechanism of the antiapoptotic effect of BPs involves activation of ERKs. Antiapoptotic agents in other cell systems transiently stimulate the phosphorylation of ERKs, members of the MAP kinase family that enhance cell survival (46-48). To probe into the mechanism of the anti-

\section{Figure 7}

Time course of ERK activation by alendronate and IG9402. (a) MLO-Y4 cells were stimulated with $10^{-7} \mathrm{M}$ alendronate (A) or IG9402 (IG) for the indicated times. Phosphorylated ERK1/2 and total ERK1/2 were determined by Western blot analysis as described in Methods. (b) Phospho-ERK/ERK ratios were obtained by quantifying the intensity of the bands in the autoradiograms using a scanner. a

b
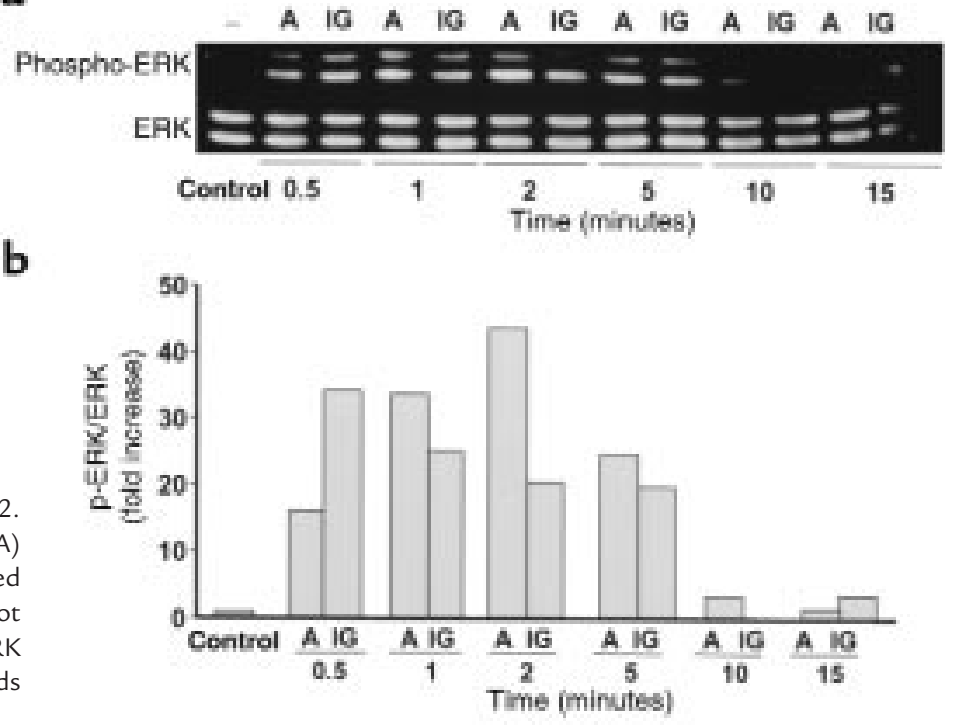
apoptotic effect of BPs, we examined whether they influenced ERK activation in MLO-Y4 osteocytic cells. Alendronate and IG9402, at $10^{-7} \mathrm{M}$, induced a rapid and transient increase in the phosphorylation of ERK 1 and 2 (Figure 7). This effect was observed as early as $0.5 \mathrm{~min}-$ utes, reached a maximum at 1-2 minutes, and decreased to basal levels by 15 minutes. The levels of total ERKs did not change upon treatment. A similar increase in the phosphorylated fraction of ERKs was induced by etidronate (Figure 8a). As expected, BP-induced phosphorylation of ERKs was abolished by pretreatment of the cells with PD98059 or by U0126, specific inhibitors of mitogen-activated protein kinase kinase $(49,50)$, the kinase responsible for phosphorylation of ERKs (Figure 8a). More importantly, pretreatment of MLO-Y4 cells with either PD98059 or U0126 abrogated the antiapoptotic effect of alendronate, IG9402, and etidronate (Figure $8, \mathrm{~b}$ and c), demonstrating that activation of ERKs is required for the antiapoptotic effect of these agents.

Calcitonin (sCT) inhibits apoptosis of osteocytic cells and osteoblasts by a mechanism that involves ERKs. Because sCT is another antiresorptive agent with antifracture properties, we next investigated whether it also influenced apoptosis of cells of the osteoblastic lineage. Previous evidence indicates the presence of calcitonin receptors in cells of the osteoblastic lineage, including osteoblastic cells from murine calvaria (51-53). To determine whether MLO-Y4 osteocytic cells expressed calcitonin receptors, a binding assay using intact cells was performed. UMR106-06 osteoblastic cells were used as a positive control. Like UMR106 cells, MLO-Y4 cells exhibited binding of $\left[{ }^{125} \mathrm{I}\right] \mathrm{sCT}$ that could be effectively competed by an excess of unlabeled sCT (Figure 9a). Consistent with the presence of specific binding, treatment of MLO-Y4 cells with SCT induced an increase in the intracellular levels of cAMP (Figure 9b). As in the case of BPs, pretreatment of MLO-Y4 or osteoblastic cells with 5-10 $\mathrm{ng} / \mathrm{mL}(1.45-2.90 \mathrm{nM}) \mathrm{sCT}$ prevented apoptosis induced by etoposide, TNF- $\alpha$, or glucocorticoids (Figure 9c). Further, $\mathrm{sCT}$ induced a rapid and transient increase in the phosphorylation of ERKs in MLO-Y4 cells. This effect was maximum at 5 minutes and decreased to basal levels by 15 minutes (Figure 10a). In addition, and as in the case of BPs, the prevention of MLO-Y4 cell apoptosis by sCT was abolished by pretreatment with either inhibitor of ERK activation, PD98059 or U0126 (Figure 10b).

Alendronate administration abolished the osteocyte and osteoblast apoptosis induced by prednisolone in vivo. Finally, to address the significance of these in vitro studies, we examined the effect of alendronate administration in a murine model of glucocorticoid excess-induced apoptosis of osteocytes and osteoblasts (21). As previously shown, administration of prednisolone decreased spinal BMD and increased the prevalence of osteoblast apoptosis in vertebral cancellous bone (Table 2; Figure 11). The increase in cancellous osteocyte apoptosis did not, however, reach significance. The higher rate of remodeling in cancellous compared with cortical bone probably did not allow the high accumulation of apoptotic osteocytes that we had previously noted in femoral metaphyseal cortical bone (21). Nonetheless, administration of alendronate, beginning 3 days before the implantation of prednisolone

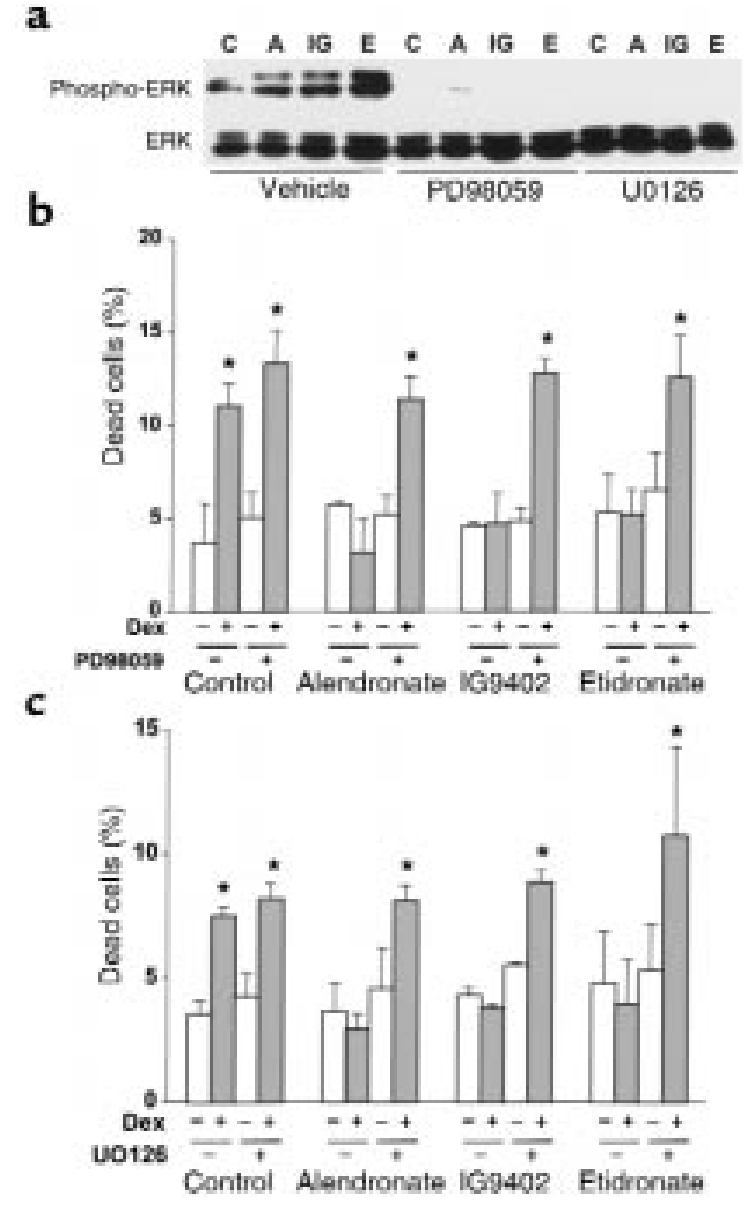

Figure 8

The antiapoptotic effect of BPs involves ERK activation. (a) Cells were incubated for 23 minutes with vehicle, $50 \mu \mathrm{M}$ PD98059, or $1 \mu \mathrm{M} \cup 0126$ before addition of $10^{-7} \mathrm{M}$ alendronate (A), IG9402 (IG), or etidronate (E) for 2 minutes. Cell lysates were obtained and assayed for the presence of phosphorylated ERK1/2 as in Figure 7. Cells were treated for 30 minutes with PD98059 (b) or with UO126 (c), followed by addition of 10-7 $\mathrm{M}$ BPs. After 1 hour, $10^{-6} \mathrm{M}$ dexamethasone was added and cultures were incubated for 6 hours. The percentage of apoptotic cells was determined by trypan blue exclusion, as in Figure 1a. Bars represent the mean \pm SD of 3 independent measurements. ${ }^{*} P<0.05$ versus control by 1 -way ANOVA (Student Newman-Keuls method).

pellets, prevented the bone loss and abolished the increase in bone cell apoptosis induced by the glucocorticoid.

The prevalence of apoptotic osteoblasts detected in this experiment by the TUNEL reaction with $\mathrm{CuSO}_{4}$ enhancement in bone sections is higher than the values obtained in our previous studies using TUNEL without $\mathrm{CuSO}_{4}(21,31)$. As detailed in our recent studies (45), this is consistent with the contention that the enhancer allows cells undergoing the DNA degradation phase to be seen at an earlier stage. Prolongation or shortening of the time that apoptosis can be observed in a specimen, as a result of using more sensitive or less sensitive detection methods, influences the prevalence of the phenomenon (45). Considering that in murine vertebral cancellous bone the wall width (W.Wi) is approximately $15 \mu \mathrm{m}$ and the mineral appositional rate (MAR) is approximately $1.25 \mu \mathrm{m} / \mathrm{d}$, the active life span of 


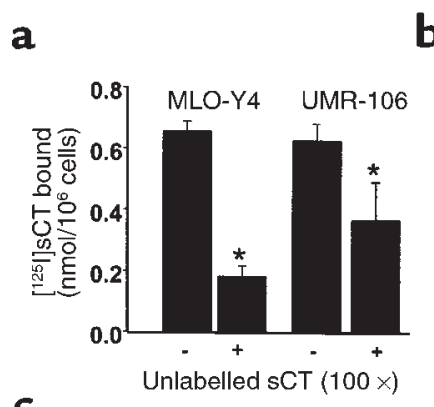

b

c

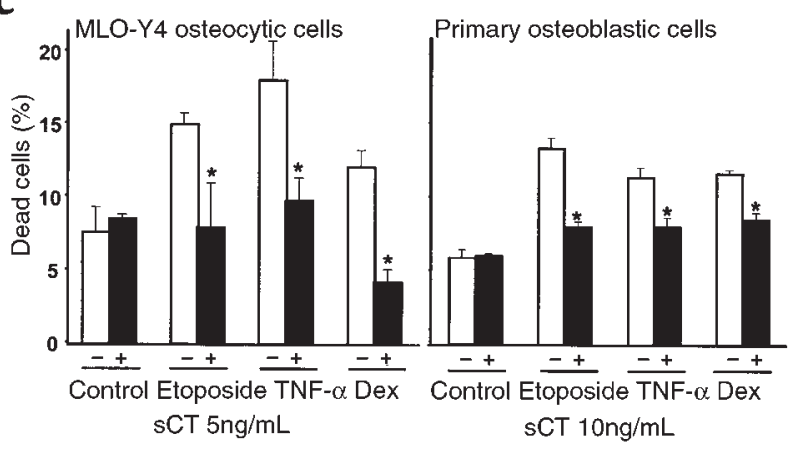

Figure 9

Salmon calcitonin inhibits glucocorticoid-, TNF- $\alpha-$, and etoposideinduced apoptosis of MLO-Y4 and osteoblastic cells. (a) MLO-Y4 or UMR-106-06 cells were incubated with $10^{-8} \mathrm{M}\left[{ }^{125} \mathrm{I}\right] \mathrm{sCT}$ in the absence or in the presence of $10^{-6} \mathrm{M}$ unlabeled $\mathrm{s} C \mathrm{C}$ for 1 hour at room temperature. After washing, bound [ $\left.{ }^{125}\right]$ sCT was determined. (b) Concentration of cAMP in MLO-Y4 cells upon treatment with $5 \mathrm{ng} / \mathrm{mL}$ of $\mathrm{sCT}$ was measured using a commercially available kit, as described in Methods. Each point represents triplicate determinations \pm SD. (c) MLO-Y4 osteocytic cells or osteoblastic cells were treated with sCT for 1 hour before the addition of the proapoptotic stimuli. The percentage of dead cells was determined by trypan blue uptake as described in Figure 1a. Bars represent the mean \pm SD of 3 independent measurements. ${ }^{*} P<0.05$ versus etoposide, TNF- $\alpha$, or dexamethasone alone by 1 -way ANOVA (Student Newman-Keuls method).

an osteoblast (W.Wi/MAR) is 12 days (288 hours) (21, 54, $55)$. If the ratio between the duration of apoptosis $\left(t_{\mathrm{Ap}}\right)$ and the active life span of an osteoblasts (288 hours) equals the prevalence of osteoblast apoptosis divided by the fraction of total osteoblasts that undergoes apoptosis at a given time $\left(f_{A \mathrm{P}}\right)$, estimated to be between 0.5 and $0.7(56)$, then the prevalence of osteoblast apoptosis of $11.34 \%$ that we found in the placebo group (Table 2) indicates that the duration of apoptosis recognized by this technique is between 46 and 65 hours. This is consistent with previous reports estimating the TUNEL-labeled phase of apoptosis from as little as 1.5 hours to as much as 48 hours, depending on the sensitivity of the technique used $(57,58)$.

\section{Discussion}

The results of the studies reported herein demonstrate that bisphosphonates inhibit osteocyte and osteoblast apoptosis, regardless of the proapoptotic stimulus used, indicating interference with a common pathway of apoptosis. These effects appear to be unrelated to the antiresorptive properties of these agents, as IG9402, a BP that does not affect osteoclast activity (44), also exhibited antiapoptotic properties on osteocytic cells and osteoblasts in the present studies. Moreover, the antiapoptotic effects of BPs were shown with concentrations approximately 3 orders of magnitude lower than those required by the same agents for the promotion of osteoclast apoptosis in vitro (5).

The inhibition of osteocytic and osteoblastic cell apoptosis in vitro was reproduced in vivo. Alendronate administration prevented the glucocorticoid-induced loss of bone and increased prevalence of osteocyte apoptosis in vertebral cancellous bone. Osteocyte experiments could have been performed in cortical bone, but osteocyte apoptosis is restricted to a narrow zone of the murine femoral metaphyseal cortex (21). To perform a more comprehensive investigation and avoid focal phenomena, we examined the lumbar vertebrae L1-L5. Vertebral cortical osteocyte apoptosis was absent, but apoptotic osteocytes and osteoblasts in the cancellous tissue were evenly distributed and, therefore, measured without bias. The prevalence of osteocyte and osteoblast apoptosis detected by the TUNEL assay is higher with than without the $\mathrm{CuSO}_{4}$ as a color enhancer $(21,31)$. Similar results were obtained in our recent study in which a direct comparison between both procedures was performed (45). This is consistent with the contention that the inclusion of $\mathrm{CuSO}_{4}$ allows cells undergoing the DNA degradation phase to be seen at an earlier stage and thereby for a longer interval. Thus, the precise inventory of the fraction of apoptotic cells in

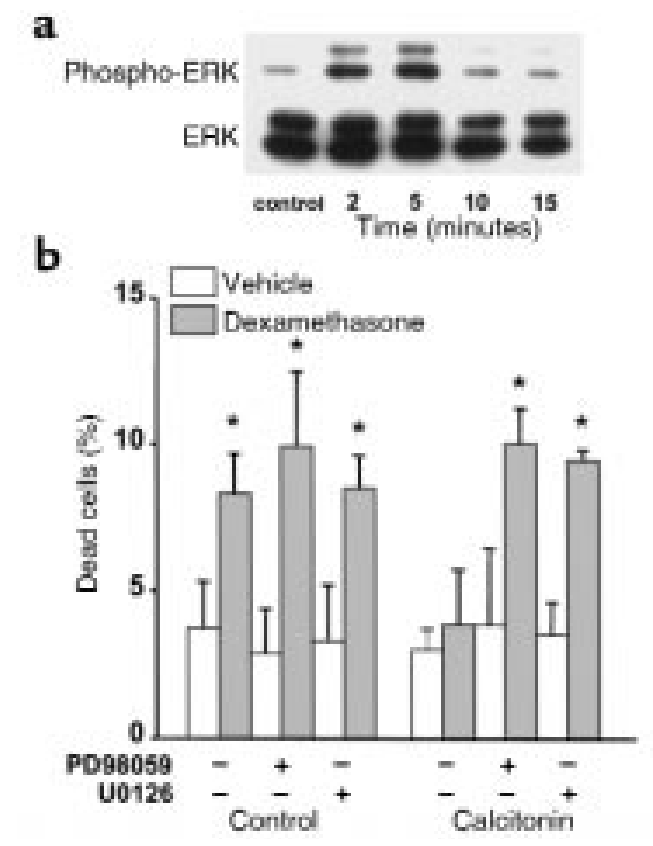

\section{Figure 10}

The antiapoptotic effect of salmon calcitonin involves ERK activation. (a) MLO-Y4 cells were stimulated with $5 \mathrm{ng} / \mathrm{mL}$ of sCT for the indicated times. Phosphorylated ERK1/2 and total ERK $1 / 2$ were determined by Western blot analysis as described in Methods. (b) Cells were treated for 30 minutes with PD98059 or with U0126, followed by addition of 5 $\mathrm{ng} / \mathrm{mL}$ of sCT. After 1 hour, $10^{-6} \mathrm{M}$ dexamethasone was added and cultures were incubated for 6 hours. The percentage of apoptotic cells was determined by trypan blue exclusion, as in Figure 1a. Bars represent the mean \pm SD of 3 independent measurements. ${ }^{*} P<0.05$ versus control by 1-way ANOVA (Student Newman-Keuls method). 


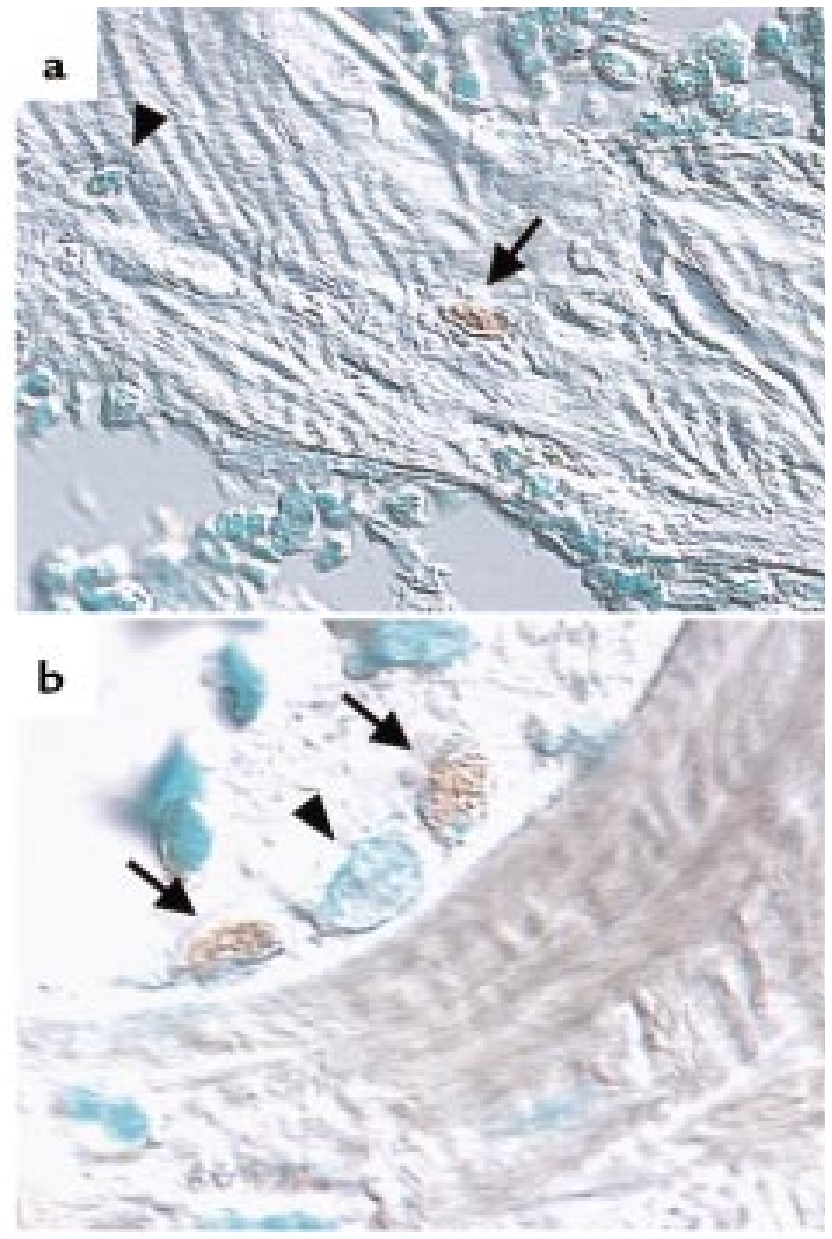

Figure 11

Effect of prednisolone on murine osteocyte and osteoblast apoptosis in vivo. Photomicrographs are from vertebral cancellous bone of mice treated for 56 days with prednisolone. Apoptotic, TUNEL-positive osteocytes (a) and osteoblasts (b) are indicated by the arrows. A normal osteocyte (a) and a normal osteoblast (b) are indicated by arrowheads. Methyl green counterstain viewed with Nomarski differential interference microscopy. Original magnification: $\times 1,000$ and $\times 630$, for $\mathbf{a}$ and $\mathbf{b}$, respectively.

bone varies depending on the identification technique and duration of the histologically recognizable features of a cell undergoing apoptosis.

The antiapoptotic action of BPs on osteocytic cells and osteoblasts involved the rapid activation of ERKs. Indeed, rapid phosphorylation of ERKs by BPs was indispensable for the effects of BPs, as their antiapoptotic effects on osteocytic cells could be completely prevented by 2 specific inhibitors of ERKs activation, PD98059 and UO126. These findings are in full agreement with evidence that the ERK family of protein kinases is activated by several other antiapoptotic agents (46-48).

In sharp contrast with the findings of the present report on osteoblasts and osteocytes, it is well established that BPs promote the apoptosis of mature osteoclasts in vitro and in vivo (5). The proapoptotic action of BPs on this cell type is probably mediated via inhibition of the mevalonate pathway, which is responsible for the synthesis of lipids utilized in posttranslational modification of proteins including prenylation (59).
Based on this evidence, it seems likely that BPs activate ERKs in osteoblastic cells in a ras-independent way, as ras activation and translocation to the membrane requires its prenylation (59). Ras-independent activation of ERKs has been recently demonstrated for parathyroid hormone (PTH) (60). Whether the activation of ERKs by BPs is also ras independent will require further studies.

We also show in this report that similar to bisphosphonates, the peptide hormone calcitonin inhibits osteocytic cell and osteoblast apoptosis, most likely via actions mediated by receptors linked to the adenylate cyclase system. These observations are in agreement with earlier findings by our group and Machwate et al. indicating that agents that increase cAMP production, such as PTH and prostaglandins, suppress apoptosis of osteocytes/osteoblasts and periosteal cells, respectively (45, 61). Therefore, it is likely that the protective effect of calcitonin on osteoblastic cells reported here is also mediated via cAMP. Further, we found that calcitonininduced ERK phosphorylation was required for its antiapoptotic effects on osteocytic cells.

The antiapoptotic effects of BPs on osteoblasts and osteocytes demonstrated in this report are in the opposite direction to their effects on the survival of osteoclasts. Opposite effects on osteoclast and osteoblast apoptosis have also been demonstrated for TGF- $\beta(31,62)$. Moreover, we have found that estrogen also inhibits osteocyte and osteoblast apoptosis (63), while promoting apoptosis of osteoclasts (62). This remarkable phenomenon of opposing effects of such diverse classes of agents on osteoblast/osteocyte versus osteoclast apoptosis strongly suggests that the signaling pathways controlling the life span of these 2 bone cell types are inherently distinct. We expect that future elucidation of the basis of these striking mechanistic differences in apoptosis should greatly advance understanding of the balance between bone resorption and formation.

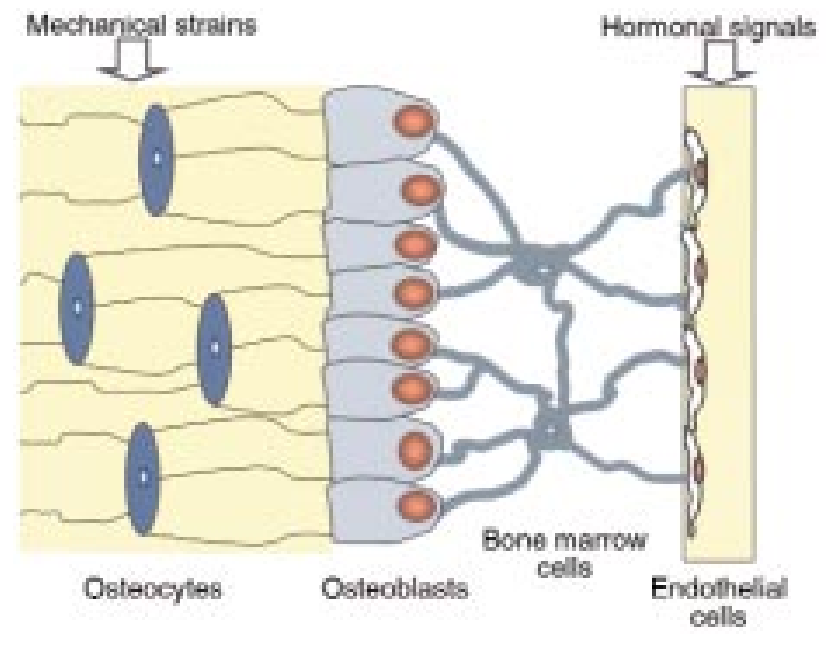

Figure 12

Functional syncytium comprising osteocytes, osteoblasts, bone marrow stromal cells, and endothelial cells. See the text for details. (Adapted with permission from G. Marotti [64].) 
Table 1

Effect of dexamethasone and alendronate on apoptosis of osteocytic MLO-Y4 cells

TUNEL-positive cells TUNEL-negative cells TUNEL-positive cells (\%)

\begin{tabular}{lccc} 
Control & 31 & 490 & 5.95 \\
Dexamethasone & 66 & 490 & $11.87^{\mathrm{A}}$ \\
Alendronate & 35 & 533 & 6.16 \\
Dexamethasone + alendronate & 35 & 507 & 6.46 \\
\hline
\end{tabular}

MLO-Y4 cells were treated for 1 hour with $10^{-7} \mathrm{M}$ alendronate or vehicle, followed by addition of dexamethasone to reach $10^{-6} \mathrm{M}$. After 6 hours, cells were fixed and the TUNEL reaction was performed as detailed in Methods. Data were obtained by counting more than 500 cells in fields selected by systematic random sampling. ${ }^{A} P<0.001$ versus control by exact $\chi^{2}$, adjusting the $P$ value using the Bonferroni correction.

the number of osteoblasts present at the site of bone formation $(21,31)$. Indeed, it has been recently shown that increased osteoblast apoptosis is at least partially responsible for the reduced bone formation in the osteopenia induced by glucocorticoid excess $(21,22)$. Conversely, we have obtained evidence that inhibition of osteoblast apoptosis is the most likely mechanism of the anabolic effect of intermittent administration of PTH (45). In this report, we show that BPs

Prolongation of the life span of osteocytes by bisphosphonates or calcitonin could explain the decrease in bone fragility that is disproportional to the gain in BMD induced by these agents $(2,16,64)$. Indeed, osteocytes, the most abundant cell type in bone, are regularly spaced throughout the mineralized matrix and communicate with each other and with cells on the bone surface via cellular processes that run along the canaliculi; osteoblasts in turn communicate with cells of the bone marrow stroma that extend cellular projections onto endothelial cells inside the sinusoids (17). Thus, a syncytium extends from the entombed osteocytes all the way to the vessel wall (65) (Figure 12). As a consequence, the strategic location of osteocytes makes them excellent candidates for mechanosensory cells able to detect the need for bone augmentation or reduction during functional adaptation of the skeleton and the need for repair of microdamage, and in both cases, to transmit signals leading to the appropriate response (66). Osteocytes evidently sense changes in interstitial fluid flow through canaliculi produced by mechanical forces (66) and detect changes in the levels of hormones such as estrogen and glucocorticoids that influence their survival and circulate in the same fluid $(21,67)$. Disruption of the osteocyte network is likely to increase bone fragility and could account for the higher incidence of fractures in glucocorticoid-treated patients compared with postmenopausal women, even though the BMD in the former is relatively higher $(19,20)$. Conversely, preservation of the osteocyte network could be one mechanism by which bisphosphonates or calcitonin decrease bone fragility.

The majority of osteoblasts die by apoptosis. Those remaining have 2 alternative fates: to become lining cells or osteocytes (31). The frequency of osteoblast apoptosis in vivo seems to be such that changes in its timing and extent could have a significant impact in

Table 2

Effect of alendronate on BMD and the prevalence of osteocyte and osteoblast apoptosis in murine vertebral cancellous bone

\begin{tabular}{lccc}
\hline Measurement & Placebo & Prednisolone & $\begin{array}{r}\text { Prednisolone } \\
+ \text { alendronate }\end{array}$ \\
Apoptotic osteocytes (\%) & $2.02 \pm 0.70$ & $2.37 \pm 0.87$ & $1.14 \pm 0.22^{\mathrm{A}}$ \\
Apoptotic osteoblasts (\%) & $11.34 \pm 4.02$ & $19.79 \pm 5.17^{\mathrm{B}}$ & $10.88 \pm 3.62^{\mathrm{A}}$ \\
Spinal BMD (\% change) & $-5.02 \pm 0.34$ & $-12.48 \pm 3.77^{\mathrm{B}}$ & $-5.46 \pm 3.52^{\mathrm{A}}$
\end{tabular}

Data shown are the mean \pm SD from 4 to 8 animals per group. ${ }^{A} P<0.05$ versus prednisolone alone, by ANOVA (Tukey test). ${ }^{B} P<0.05$ versus placebo, by ANOVA (Tukey test). increase the survival of osteoblastic cells. Although we found similar antiapoptotic effects of PTH and BPs in vitro, the in vivo effects of BPs on bone formation are not as readily demonstrated as those of intermittent PTH administration, probably because the slowing of remodeling by the former agents reduces the extent of osteoblast covered surface. But where osteoblasts are present, more bone is made, indicated by an increase in wall thickness $(12-14,68)$.

The results reported here could also be of importance to the recognized actions of bisphosphonates on the origination and/or progression of the basic multicellular unit (BMU). It has been proposed that targeting of osteoclast precursors to a specific location on bone depends on a "homing" signal given by lining cells and that lining cells are instructed to do so by osteocytes (the only bone cells that can sense the need for remodeling at a specific time and place) (7). This, and the evidence that BPs affect osteoclasts not only directly but also indirectly via effects on osteoblastic cells (9-11), raise the possibility that prolongation of the life span of osteocytes (and osteoblastic cells in general) may contribute to the reduction in the frequency of origination and/or premature termination of BMU progression that characterizes the decrease in bone resorption induced by bisphosphonates $(2,7)$.

In conclusion, the studies reported here raise the possibility that increased survival of osteoblasts and osteocytes may both contribute to the efficacy of bisphosphonates and calcitonin in the management of disease states due to loss of bone, such as glucocorticoid-induced osteoporosis. An increase in osteoblast work time may lead to a gradual increase in trabecular thickness, and preservation of osteocytes may contribute to the antifracture efficacy of these agents, which is disproportional to the relatively modest increase in BMD. 
Health (PO1AG/AMS13918, RO1AR43003, RO1 AR46191, RO1 AG13918, and R29AR43453) and by the Department of Veterans Affairs (VA Merit grants to S.C. Manolagas and R.S. Weinstein). Partial support for L.I. Plotkin was provided by a grant from Gador S.A.

1. Fleisch, H. 1997. Bisphosphonates in bone disease. From the laboratory to the patient. The Parthenon Publishing Group Inc. New York, NY. 32-163.

2. Papapoulos, S. 1996. Bisphosphonates. Pharmacology and use in the treatment of osteoporosis. In Osteoporosis. R. Marcus, D. Feldman, and J. Kelsey, editors. Academic Press. San Diego, CA. 1209-1234.

3. Rodan, G.A., and Fleisch, H.A. 1996. Bisphosphonates: mechanisms of action. J. Clin. Invest. 97:2692-2696.

4. Azria, M., and Avioli, L.V. 1996. Calcitonin. In Principles of bone biology. J.P. Bilezikian, L.G. Raisz, and G.A. Rodan, editors. Academic Press. San Diego, CA. 1083-1097.

5. Hughes, D.E., et al. 1995. Bisphosphonates promote apoptosis in murine osteoclasts in vitro and in vivo. J. Bone Miner. Res. 10:1478-1487.

6. Hughes, D.E., MacDonald, B.R., Russell, R.G., and Gowen, M. 1989. Inhibition of osteoclast-like cell formation by bisphosphonates in long-term cultures of human bone marrow. J. Clin. Invest. 83:1930-1935.

7. Parfitt, A.M., Mundy, G.R., Roodman, G.D., Hughes, D.E., and Boyce, B.F. 1996. A new model for the regulation of bone resorption, with particular reference to the effects of bisphosphonates. J. Bone Miner. Res $11: 150-159$.

8. Jilka, R.L., et al. 1998. Loss of estrogen upregulates osteoblastogenesis in the murine bone marrow: evidence for autonomy from factors released during bone resorption. J. Clin. Invest. 101:1942-1950.

9. Nishikawa, M., et al. 1996. Bisphosphonates act on osteoblastic cells and inhibit osteoclast formation in mouse marrow cultures. Bone. 18:9-14

10. Sahni, M., Guenther, H.L., Fleisch, H., Collin, P., and Martin, T.J. 1993. Bisphosphonates act on rat bone resorption through the mediation of osteoblasts. J. Clin. Invest. 91:2004-2011.

11. Vitte, C., Fleisch, H., and Guenther, H.L. 1996. Bisphosphonates induce osteoblasts to secrete an inhibitor of osteoclast-mediated resorption. Endocrinology. 137:2324-2333.

12. Chavassieux, P.M., et al. 1997. Histomorphometric assessment of the long-term effects of alendronate on bone quality and remodeling in patients with osteoporosis. J. Clin. Invest. 100:1475-1480.

13. Balena, R., et al. 1993. The effects of 2 -year treatment with the aminobisphosphonate alendronate on bone metabolism, bone histomorphometry, and bone strength in ovariectomized nonhuman primates. $J$. Clin. Invest. 92:2577-2586.

14. Storm, T., Steiniche, T., Thamsborg, G., and Melsen, F. 1993. Changes in bone histomorphometry after long-term treatment with intermittent, cyclic etidronate for postmenopausal osteoporosis. J. Bone Miner. Res. 8:199-208.

15. Dempster, D.W. 1997. Exploiting and bypassing the bone remodeling cycle to optimize treatment of osteioporosis. J. Bone Miner. Res. 12:1152-1154.

16. Cummings, S.R., Black, D.M., and Vogt, T.M. 1996. Changes in BMD substantially underestimate the anti-fracture effects of alendronate and other antiresorptive drugs. J. Bone Miner. Res. 11(Suppl.):S102. (Abstr.)

17. Marotti, G., Cane, V., Palazzini, S., and Palumbo, C. 1990. Structurefunction relationships in the osteocyte. Ital. J. Miner. Electrol. Metab. 4:93-106

18. Nijweide, P.J., Burger, E.H., Klein-Nulend, J., and Van Der Plas, A. 1996. The osteocyte. In Principles of bone biology. J.P. Bilezikian, L.G. Raisz, and G.A. Rodan, editors. Academic Press. San Diego, CA. 115-126.

19. Peel, N.F., Moore, D.J., Barrington, N.A., Bax, D.E., and Eastell, R. 1995. Risk of vertebral fracture and relationship to bone mineral density in steroid treated rheumatoid arthritis. Ann. Rheum. Dis. 54:801-806.

20. Dennison, E. 1999. Epidemiology of glucocorticoid-induced osteoporosis. Osteoporosis Int. 9:S16. (Abstr.)

21. Weinstein, R.S., Jilka, R.L., Parfitt, A.M., and Manolagas, S.C. 1998. Inhibition of osteoblastogenesis and promotion of apoptosis of osteoblasts and osteocytes by glucocorticoids: potential mechanisms of their deleterious effects on bone. J. Clin. Invest. 102:274-282.

22. Weinstein, R.S., et al. 1998. Anatomic juxtaposition of apoptotic osteocytes and avascular necrosis in femurs from patients with glucocorticoid excess. Bone. 23(Suppl):S461. (Abstr.)

23. Reid, I.R., Schooler, B.A., and Stewart, A.W. 1990. Prevention of glucocorticoid-induced osteoporosis. J. Bone Miner. Res. 5:619-623.

24. Gonnelli, S., et al. 1997. Prevention of corticosteroid-induced osteoporosis with alendronate in sarcoid patients. Calcif. Tissue Int. 61:382-385.

25. Falcini, F., Trapani, S., Ermini, M., and Brandi, M.L. 1996. Intravenous administration of alendronate counteracts the in vivo effects of glucocorticoids on bone remodeling. Calcif. Tissue Int. 58:166-169.

26. Kato, Y., Windle, J.J., Koop, B.A., Mundy, G.R., and Bonewald, L.F. 1997. Establishment of an osteocyte-like cell line, MLO-Y4. J. Bone Miner. Res.
12:2014-2023.

27. Bellido, T., Borba, V.Z.C., Roberson, P.K., and Manolagas, S.C. 1997. Activation of the JAK/STAT signal transduction pathway by IL-6 type cytokines promotes osteoblast differentiation. Endocrinology. 138:3666-3676

28. Sakagami, Y., Girasole, G., Yu, X.-P., Boswell, H.S., and Manolagas, S.C. 1993. Stimulation of interleukin-6 production by either calcitonin generelated peptide or parathyroid hormone in two phenotypically distinct bone marrow-derived murine stromal cell lines. J. Bone Miner. Res. 8:811-816

29. Kalderon, D., Roberts, B.L., Richardson, W.D., and Smith, A.E. 1984. A short amino acid sequence able to specify nuclear location. Cell. 39:499-509.

30. Grignani, F., et al. 1998. High-efficiency gene transfer and selection of human hematopoietic progenitor cells with a hybrid EBV/retroviral vector expressing the green fluorescence protein. Cancer Res. 58:14-19.

31. Jilka, R.L., Weinstein, R.S., Bellido, T., Parfitt, A.M., and Manolagas, S.C. 1998. Osteoblast programmed cell death (apoptosis): modulation by growth factors and cytokines. J. Bone Miner. Res. 13:793-802.

32. Schlegel, J., et al. 1996. CPP32/apopain is a key interleukin 1 beta converting enzyme-like protease involved in Fas-mediated apoptosis. J. Biol. Chem. 271:1841-1844.

33. Borchard, R.E., Barbes, C.D., and Eltherington, L.G. 1992. Drug dosage in laboratory animals: a handbook. CRC Press, Inc. Boca Raton, FL. 514 pp.

34. Kleiber, M. 1961. The fire of life: an introduction to animal energetics. John Wiley \& Sons Inc. New York, NY. 177-230.

35. Reichardt, H.M., et al. 1998. DNA binding of the glucocorticoid receptor is not essential for survival [see comments]. Cell. 93:531-541.

36. Chauhan, D., et al. 1997. Dexamethasone induces apoptosis of multiple myeloma cells in a JNK/SAP kinase independent mechanism. Oncogene. 15:837-843.

37. Clevenger, C.V., et al. 1997. Role of Bag-1 in the survival and proliferation of the cytokine-dependent lymphocyte lines, Ba/F3 and Nb2. Mol. Endocrinol. 11:608-618.

38. Stefanelli, C., et al. 1998. Inhibition of etoposide-induced apoptosis with peptide aldehyde inhibitors of proteasome. Biochem. J. 332:661-665.

39. Ashkenazi, A., and V.M., Dixit. 1998. Death receptors: signaling and modulation. Science. 281:1305-1308.

40. Thornberry, N.A., and Lazebnik, Y. 1998. Caspases: enemies within. Science. 281:1312-1316.

41. Giuliani, N., et al. 1995. Alendronate stimulates b-FGF production and mineralized nodule formation in human osteoblastic cells and osteoblastogenesis in human bone marrow cultures. J. Bone Miner. Res. 10(Suppl):S171. (Abstr.)

42. Giuliani, N., et al. 1998. Bisphosphonates stimulate formation of osteoblast precursors and mineralized nodules in murine and human bone marrow cultures in vitro and promote early osteoblastogenesis in young and aged mice in vivo. Bone. 22:455-461.

43. Tenenbaum, H.C., Torontali, M., and Sukhu, B. 1992. Effects of bisphosphonates and inorganic pyrophosphate on osteogenesis in vitro. Bone. 13:249-255.

44. Van Beek, E., Lowik, C., Que, I., and Papapoulos, S. 1998. Dissociation of binding and antiresorptive properties of hydroxybisphosphonates by substitution of the hydroxyl with an amino group. J. Bone Miner. Res. 11:1492-1497.

45. Jilka, R.L., et al. 1999. Increased bone formation by prevention of osteoblast apoptosis with PTH. J. Clin. Invest. 104:439-446.

46. Xia, Z., Dickens, M., Raingeaud, J., Davis, R.J., and Greenberg, M.E. 1995. Opposing effects of ERK and JNK-p38 MAP kinases on apoptosis. Science. 270:1326-1331.

47. Gardner, A.M., and Johnson, G.L. 1996. Fibroblast growth factor-2 suppression of tumor necrosis factor alpha-mediated apoptosis requires Ras and the activation of mitogen-activated protein kinase. J. Biol. Chem. 271:14560-14566.

48. Wang, X., Martindale, J.L., Liu, Y., and Holbrook, N.J. 1998. The cellular response to oxidative stress: influences of mitogen-activated protein kinase signalling pathways on cell survival. Biochem. J. 333:291-300.

49. Alessi, D.R., Cuenda, A., Cohen, P., Dudley, D.T., and Saltiel, A.R. 1995. PD 098059 is a specific inhibitor of the activation of mitogen-activated protein kinase kinase in vitro and in vivo. J. Biol. Chem. 270:27489-27494.

50. Favata, M.F., et al. 1998. Identification of a novel inhibitor of mitogenactivated protein kinase kinase. J. Biol. Chem. 273:18623-18632.

51. Forrest, S.M., et al. 1985. Characterization of an osteoblast-like clonal cell line which responds to both parathyroid hormone and calcitonin. Calcif. Tissue Int. 37:51-56.

52. Iida-Klein, A., Yee, D.C., Brandli, D.W., Mirikitani, E.J., and Hahn, T.J. 1992. Effects of calcitonin on 3',5'-cyclic adenosine monophosphate and calcium second messenger generation and osteoblast function in UMR 106-06 osteoblast-like cells. Endocrinology. 130:381-388.

53. Farley, J.R., Wergedal, J.E., Hall, S.L., Herring, S., and Tarbaux, N.M. 1991. Calcitonin has direct effects on $3[\mathrm{H}]$-thymidine incorporation and alkaline phosphatase activity in human osteoblast-line cells. Calcif. Tissue Int. 48:297-301 
54. Weinstein, R.S., Jilka, R.L., Parfitt, A.M., and Manolagas, S.C. 1997. The effects of androgen deficiency on murine bone remodeling and bone mineral density are mediated via cells of the osteoblastic lineage. Endocrinology. 138:4005-4012.

55. Jilka, R.L., Weinstein, R.S., Takahashi, K., Parfitt, A.M., and Manolagas, S.C. 1996. Linkage of decreased bone mass with impaired osteoblastogenesis in a murine model of accelerated senescence. J. Clin. Invest. 97:1732-1740.

56. Parfitt, A.M. 1990. Bone-forming cells in clinical conditions. In Bone. Volume 1. The osteoblast and osteocyte. B.K. Hall, editor. CRC Press. Boca Raton, FL. 351-430.

57. Bursch, W., Paffe, S., Putz, B., Barthel, G., and Schulte-Hermann, R. 1990. Determination of the length of the histological stages of apoptosis in normal liver and in altered hepatic foci of rats. Carcinogenesis. 11:847-853.

58. Pompeiano, M., Hvala, M., and Chun, J. 1998. Onset of apoptotic DNA fragmentation can precede cell elimination by days in the small intestinal villus. Cell Death Differ. 5:702-709.

59. Luckman, S.P., et al. 1998. Nitrogen-containing bisphosphonates inhibit the mevalonate pathway and prevent post-translational prenylation of GTP-binding proteins, including Ras. J. Bone Miner. Res. 13:581-589.

60. Verheijen, M.H., and Defize, L.H. 1997. Parathyroid hormone activates mitogen-activated protein kinase via a cAMP-mediated pathway inde- pendent of Ras. J. Biol. Chem 272:3423-3429.

61. Machwate, M., Rodan, S.B., Rodan, G.A., and Harada, S.I. 1998. Sphingosine kinase mediates cyclic AMP suppression of apoptosis in rat periosteal cells. Mol. Pharmacol. 54:70-77.

62. Hughes, D.E., et al. 1996. Estrogen promotes apoptosis of murine osteoclasts mediated by TGF-beta. Nat. Med. 2:1132-1136.

63. Manolagas, S.C., Weinstein, R.S., Bellido, T., and Bodenner, D.L. 1999. Opposite effects of estrogen on the life span of osteoblasts/osteocytes versus osteoclasts in vivo and in vitro: an explanation of the imbalance between formation and resorption in estrogen deficiency. J. Bone Miner. Res. 14:S169. (Abstr.)

64. Glorieux, F.H., et al. 1998. Cyclic administration of pamidronate in children with severe osteogenesis imperfecta. N. Engl. J. Med. 339:947-952.

65. Marotti, G. 1996. The structure of bone tissues and the cellular control of their deposition. Ital. J. Anat. Embryol. 101:25-79.

66. Aarden, E.M., Burger, E.H., and Nijweide, P.J. 1994. Function of osteocytes in bone. J. Cell Biochem. 55:287-299.

67. Noble, B.S., Stevens, H., Loveridge, N., and Reeve, J. 1997. Identification of apoptotic changes in osteocytes in normal and pathological human bone. Bone. 20:273-282.

68. Boyce, R.W., Paddock, C.L., Gleason, J.R., Sletsema, W.K., and Eriksen, E.F. 1995. The effects of risedronate on canine cancellous bone remodeling: three-dimensional kinetic reconstruction of the remodeling site. J. Bone Miner. Res. 10:211-221. 